\title{
THE INFLUENCE OF NITROGEN ON THE DECOMPOSITION OF CROP RESIDUES IN THE SOIL
}

\author{
H. Lueken ${ }^{2}$, W. L. Hutcheon and E. A. Paul ${ }^{3}$ \\ University of Saskatchewan, Saskatoon, Saskatchewan \\ [Received for publication March 7, 1962]
}

\begin{abstract}
Additions of mineral nitrogen accelerated the initial decomposition rate of incorporated wheat straw, alfalfa hay and glucose when added to two soils differing widely in organic matter content. However, in the more advanced stages of decomposition the reverse was true, and over the total incubation period larger amounts of carbon were maintained in soils supplemented with nitrogen.

In contrast to all other residues used, nitrogen additions to cellulose effected a continuous and substantial increase in residue decomposition. This was the only residue for which the mineralization of soil organic matter did not supply nitrogen adequate for its decomposition within 120 days.

The very slow rate of decomposition of sphagnum peat could be attributed to its high lignin content, rather than to the nitrogen levels.

Sulphacetolysis analysis, which measures the non-humified carbon, indicated the feasibility of separating non-humified crop residues from the more complex soil organic matter. Addition of organic amendments thus resulted in a drop in the soil humification quoticnt. Nitrogen resulted in the retention of a significantly higher percentage of the added residue, without a drop in the humification quotiont for the high organic matter Melfort soil.

Residue applications to soils produced a significant improvement of structural development, especially in the low organic matter soil (Arborfield).
\end{abstract}

\section{INTRODUCTION}

The long-term effect of nitrogen on the transformation of organic carbon within the soil, although of principal importance, is not clearly established. Since humus has been found to contain a fairly constant level of nitrogen under comparative environmental conditions $(2,12)$ it is usually argued that humus synthesis from crop residues, or other added organic amendments, cannot occur unless sufficient nitrogen is present. Inorganic nitrogen additions to a residue usually stimulate the initial rate of decomposition. This may lead to a higher degree of humification of the original plant remains, but not necessarily to a build-up of the soil organic matter level. Lee and Bray (3), Salter (10), and Turk and Millar (16) consider that added nitrogen is of principal importance for the prevention of excessive carbon loss. Other investigators utilizing different soils and environmental conditions have come to the opposite conclusion $(8,17)$.

There are also experimental results indicating insignificant differences in decomposition between nitrogen-treated and untreated residues in soil $(4,11)$. Newton $(6)$, studying decomposition rates of incorporated wheat straw in Podzolic Grey Wooded, Chernozemic Black and Chernozemic Brown soils, did not obtain any significant responses in $\mathrm{CO}_{2}$ evolution to fertilization with nitrogen.

1Contribution from the Department of Soil Science, University of Saskatchewan, Saskatoon, Sask, 9Formerly Research Officer, Indian Head Experimental Farm; now at Bundesanstalt für Bodenforschung, Hannover, Germany.

'Professor, and Assistant Professor, of Soil Science, respectively. 
This study was conducted to investigate the problem of maintaining soil organic matter by the addition of various residue materials, with differing nitrogen levels, to two cultivated mineral soils of different organic matter content. Quantitative carbon mineralization studies, by means of measuring $\mathrm{CO}_{2}$ production, and a qualitative characterization of the humus fraction, were used in an attempt to resolve the discrepancies among previously published reports.

\section{MATERIALS AND METHODS}

The two soils used in this study were obtained from the cultivated Ap horizon of an Orthic Black silty clay (Melfort Association), and a Grey Wooded Solodized Solonetz clay loam (Arborfield Association), respectively (5). Both soils were developed on fine textured, glacial-lacustrine parent material. They are both free of inorganic carbonate, but differ markedly in soil organic matter content. Some of the more important physical and chemical characteristics of the two soils are shown in Table 1.

Particle size distribution was determined by the pipette method, and $\mathrm{pH}$ values on a saturated paste. The organic carbon was determined by the dry combustion technique, and nitrogen by using the micro-Kjeldahl procedure.

Table 2 shows the composition of the five organic residues used in this study. Wheat straw, alfalfa hay and sphagnum moss were applied to the soil in a finely ground form. The cellulose was derived from shredded filter paper, and glucose was an analytical reagent. Total phosphorus in the residues was determined by the molybdo-phosphoric blue color method (14) after wet digestion of the material.

Table 1. - Physical and chemical properties of the solls

\begin{tabular}{|c|c|c|c|c|c|c|c|c|c|}
\hline \multirow{2}{*}{$\begin{array}{l}\text { Type } \\
\text { of soil }\end{array}$} & \multicolumn{3}{|c|}{ Percentage $^{1}$} & \multirow{2}{*}{$\mathrm{pH}$} & \multirow{2}{*}{$\begin{array}{c}\text { Org. } \\
\text { carbon } \\
\%\end{array}$} & \multirow{2}{*}{$\underset{\%}{\text { Nitrogen }}$} & \multirow{2}{*}{$\begin{array}{l}\mathrm{C} / \mathrm{N} \\
\text { ratio }\end{array}$} & \multirow{2}{*}{$\begin{array}{c}\text { Hyg. } \\
\text { moist. } \\
\%\end{array}$} & \multirow{2}{*}{$\underset{\%}{1 / 3}$} \\
\hline & Sand & Silt & Clay & & & & & & \\
\hline Melfort & 18.7 & 41.6 & 39.7 & 6.40 & 6.00 & 0.491 & 12.22 & 4.40 & 38 \\
\hline Arborfield & 37.0 & 38.0 & 25.0 & 5.85 & 1.64 & 0.131 & 12.52 & 1.24 & 23 \\
\hline
\end{tabular}

${ }^{\mathrm{I}}$ Sand: $2 \mathrm{~mm}$. to $0.05 \mathrm{~mm}$.

Silt: $0.05 \mathrm{~mm}$. to $0.002 \mathrm{~mm}$.

Clay: finer than $0.002 \mathrm{~mm}$

Table 2. - Chemical properties of the organic residues

\begin{tabular}{l|c|c|c}
\hline \multicolumn{1}{c|}{ Organic compound } & $\% \mathrm{C}$ & $\% \mathrm{~N}$ & $\% \mathrm{P}$ \\
\hline Wheat straw & 47.1 & 0.787 & 0.078 \\
Alfalta & 45.3 & 2.378 & 0.134 \\
Sphagnum peat & 45.3 & 0.713 & 0.050 \\
Cellulose (filter paper) & 41.0 & none & none \\
Glucose (pure chemical) & 40.0 & none & none \\
\hline
\end{tabular}


Fifty grams of soil, plus residue applied at a rate corresponding to 4 , 20 or 40 tons per acre (0.4,2 and 4 per cent respectively) were incubated in 500-milliliter Erlenmeyer flasks. All residues were adjusted to a uniform carbon-phosphorus ratio (250 to 1 ) by the addition of $\mathrm{K}_{2} \mathrm{HPO}_{4}$. The carbon to nitrogen ratios of the residues were adjusted by the addition of $\mathrm{NH}_{4} \mathrm{NO}_{3}$. The rate of decay of the incorporated residue was followed by measuring the evolved $\mathrm{CO}_{2}$ using an aeration train; the $\mathrm{CO}_{2}$ was collected in $0.5 \mathrm{~N} \mathrm{NaOH}$ scrubbers filled with "Berl Saddles" to increase the absorbing surface. All $\mathrm{CO}_{2}$ values obtained from the incorporated residues were adjusted for $\mathrm{CO}_{2}$ evolved from an untreated check soil during the same period. The moisture content of the samples was maintained at approximately 70 per cent of the field capacity and the samples were incubated at room temperature.

The organic matter in some of the incubated treatments was fractionated by Springer's sulphacetolysis technique $(13,15)$. The extracting solvent consisted of a mixture of glacial acetic acid, acetic anhydride, and sulphuric acid. This treatment dissolves certain organic matter fractions which are characterized by a low degree of polymerization, and low nitrogen content. These soluble fractions of organic matter consist chiefly of humolignin acids and fulvic acids, while the insoluble part contains humic acids.

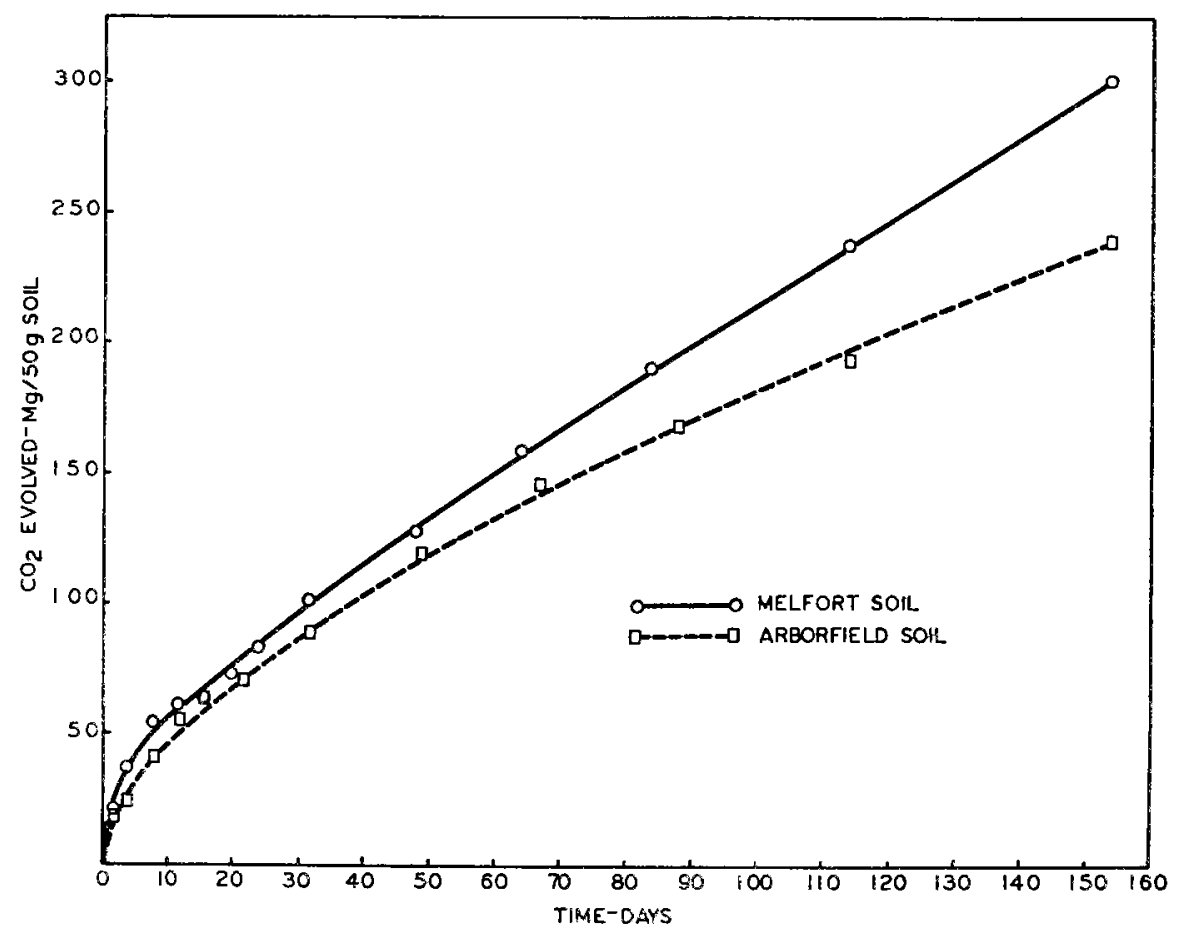

Figure 1. Cumulative $\mathrm{CO}_{2}$ evolution from untreated soils. 
The soil organic matter was further characterized following, in principle, the procedure as described by Reissig (9). This procedure did not indicate any differences in organic matter composition attributable to crop residues.

\section{RESULTS}

The respiratory activity of the unamended soil samples is shown in Figure 1. A comparison of the curves indicates slightly higher $\mathrm{CO}_{2}$ evaluation from the Melfort soil sample than from the Arborfield soil. When expressed as a per cent of soil organic matter mineralized, however, the Melfort soil sample lost 2.74 per cent and the Arborfield 7.95 per cent of its organic matter during the 150 -day incubation period.

The effect of nitrogen fertilization on the evolution of $\mathrm{CO}_{2}$ from the high organic matter Melfort soil, and of calcium on the evolution from the slightly acidic Arborfield soil, was also determined. The addition of 0.078 per cent nitrogen to the Melfort soil, without added residue, resulted in a 63 per cent increase in $\mathrm{CO}_{2}$ evolved during a 32-day incubation period. Similarly, raising the $\mathrm{pH}$ of the Arborfield soil sample to approximately neutral by the addition of calcium hydroxide resulted in an enhanced de-

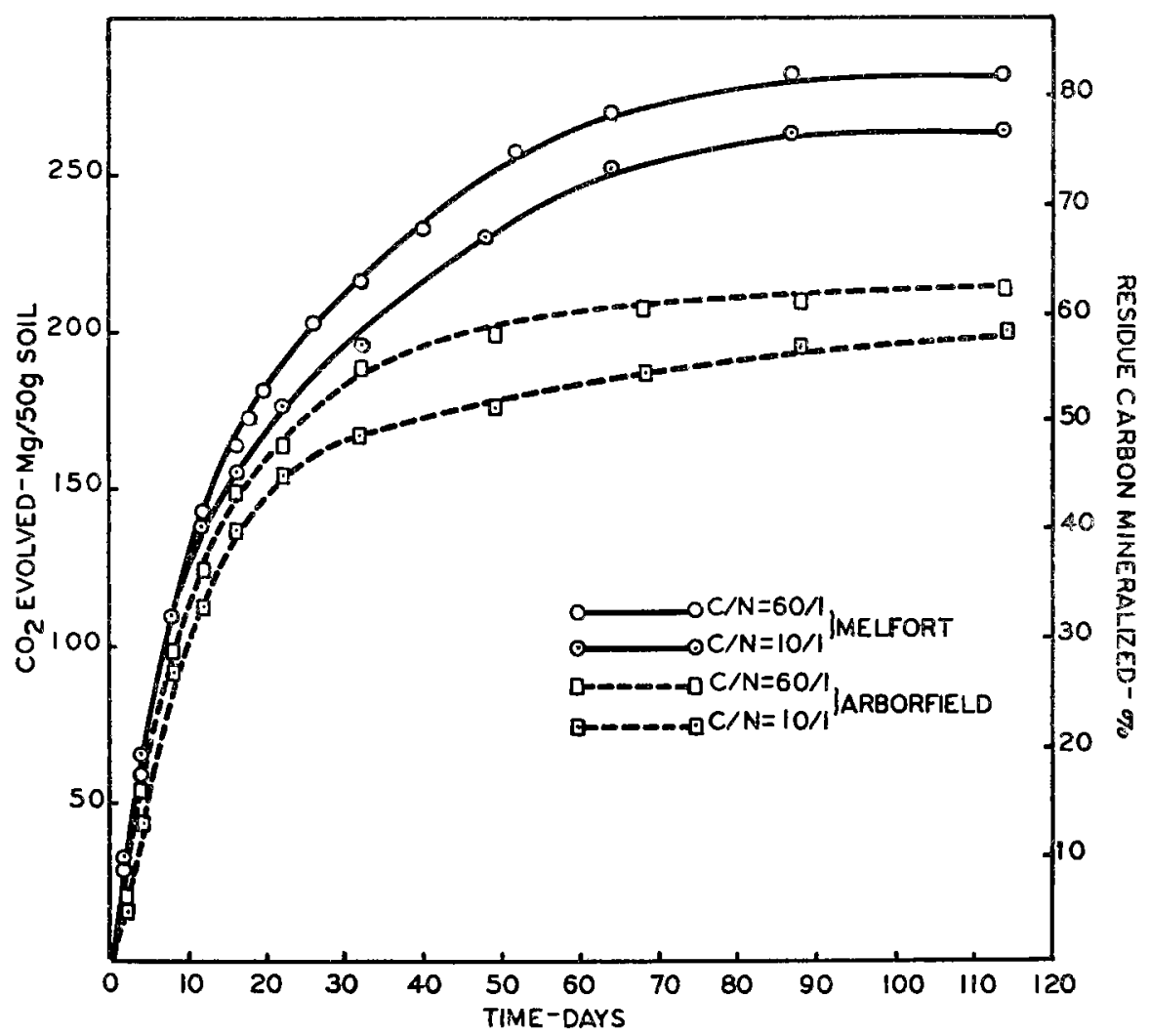

FIgURE 2. Effect of nitrogen on cumulative $\mathrm{CO}_{2}$ evolution from soils incubated with 4 tons of straw per acre. 
composition rate. Sixty-five milligrams of calcium hydroxide increased the total amount of $\mathrm{CO}_{2}$ evolved from 153 to 274 milligrams.

\section{Decomposition of Strow and Alfalfa}

Figure 2 illustrates the cumulative $\mathrm{CO}_{2}$ evolution obtained from the two soils treated with wheat straw at a rate equivalent to 4 tons per acre. Alteration of the original carbon to nitrogen ratio of the straw from $60 / 1$ to $10 / 1$ by the addition of nitrogen resulted in a reduced $\mathrm{CO}_{2}$ production during the 114-day incubation period. After $2 \frac{1}{2}$ months, the rate of mineralization of the straw was practically zero in both soils. Approximately 20 per cent of the added residue was not accounted for by the $\mathrm{CO}_{2}$ evolved and is assumed to be a contribution to soil organic matter.

Figure 3 shows the cumulative $\mathrm{CO}_{2}$ production curves for the two soils treated with a straw application equivalent to 40 tons per acre. The nitrogen-treated samples had higher initial decay rates during the first 3 weeks of incubation but lower rates thereafter. Nitrogen fertilization again resulted in a net reduction in total $\mathrm{CO}_{2}$ evolved during the incubation period. The secondary $\mathrm{CO}_{2}$ evolution peak observed during the 60 - to 100-day period in the soil-straw mixture in the Arborfield soil was accompanied by intensive growth of fungal mycelia. Additional experiments with 20 tons of straw per acre adjusted to carbon to nitrogen ratios varying from $10 / 1$ to $60 / 1$ produced comparable results.

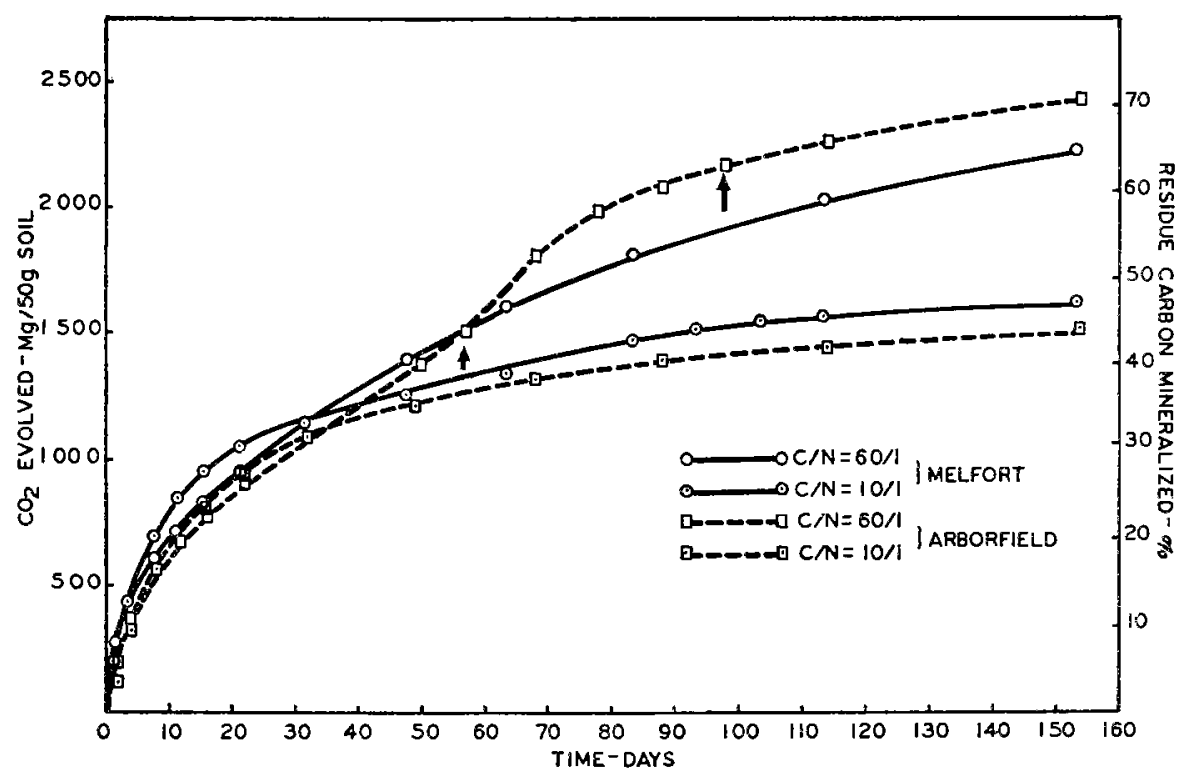

Figure 3. Effect of nitrogen on cumulative $\mathrm{CO}_{2}$ evolution from soils incubated with 40 tons of wheat straw per acre. Between arrows: abundant fungi mycelia growth in Arborfield soil mixture. 


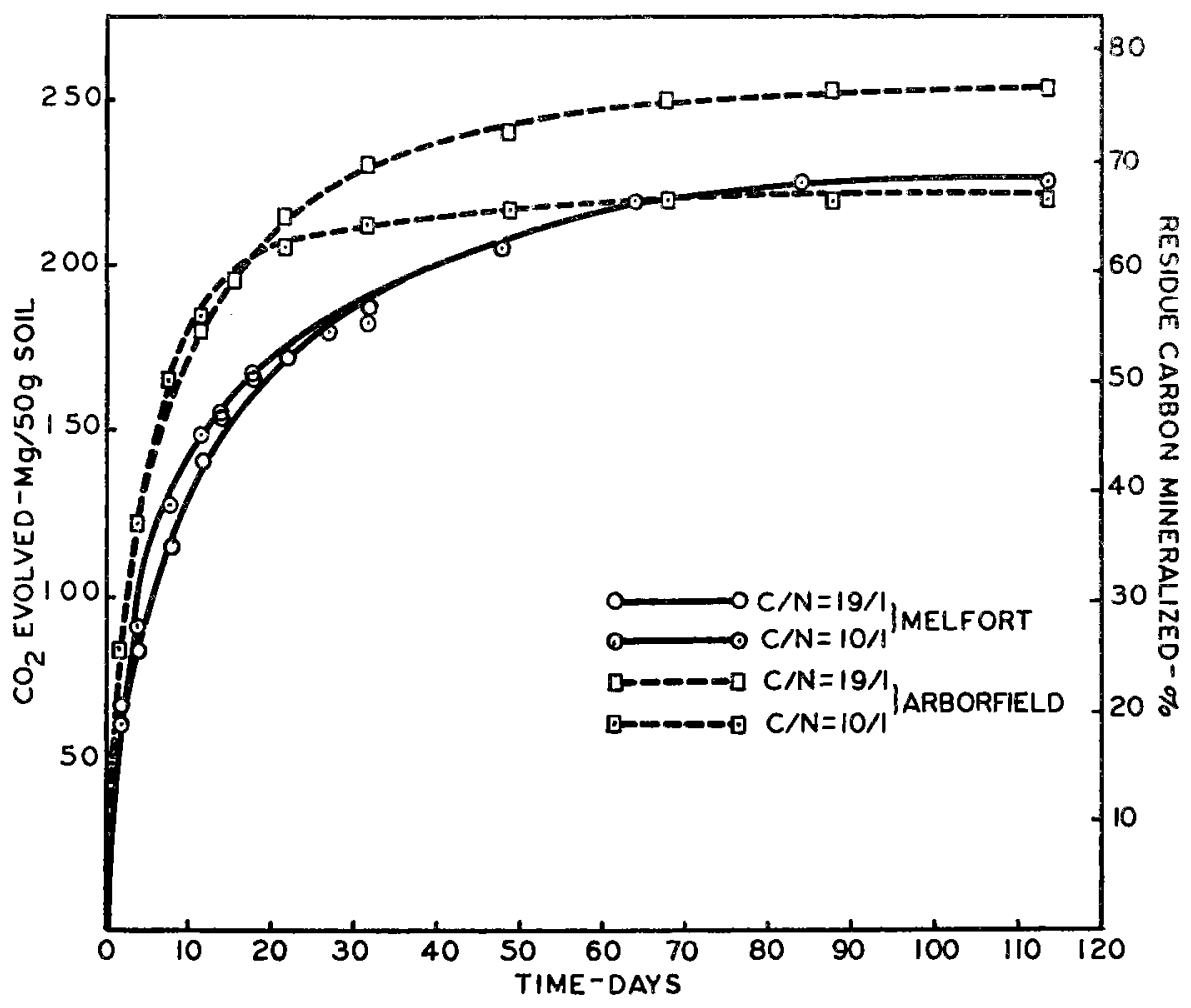

Figure 4. Effect of nitrogen on cumulative $\mathrm{CO}_{z}$ evolution from soils incubated with 4 tons of alfalfa per acre.

Figures 4 and 5 represent cumulative $\mathrm{CO}_{2}$ evolution curves obtained from the two soils treated with the equivalent of 4 and 40 tons per acre, respectively, of finely ground alfalfa hay having a $\mathrm{C} / \mathrm{N}$ ratio of $19 / 1$. At the lower level of residue addition, no effect due to the added nitrogen was observed for the Melfort soil; the Arborfield soil, however, which is low in organic matter, had a net decrease of $\mathrm{CO}_{2}$ evolution. The decomposition reactions occurring in the 4-tons-per-acre-of-alfalfa treatment were practically completed in both soils by the end of 114 days with approximately 70 per cent of the carbon of the residue evolved as $\mathrm{CO}_{2}$.

A comparison between the 40-tons-per-acre application of alfalfa and wheat straw indicates that alfalfa had a much higher initial rate of decay than the straw. This, however, was reversed in the more advanced stages of decomposition. Where the straw was not supplemented with nitrogen, $\mathrm{CO}_{2}$ was still being evolved at a substantial rate, even after 150 days. In the comparable alfalfa treatments the evolution rate had, however, levelled off after 30 days' incubation. 


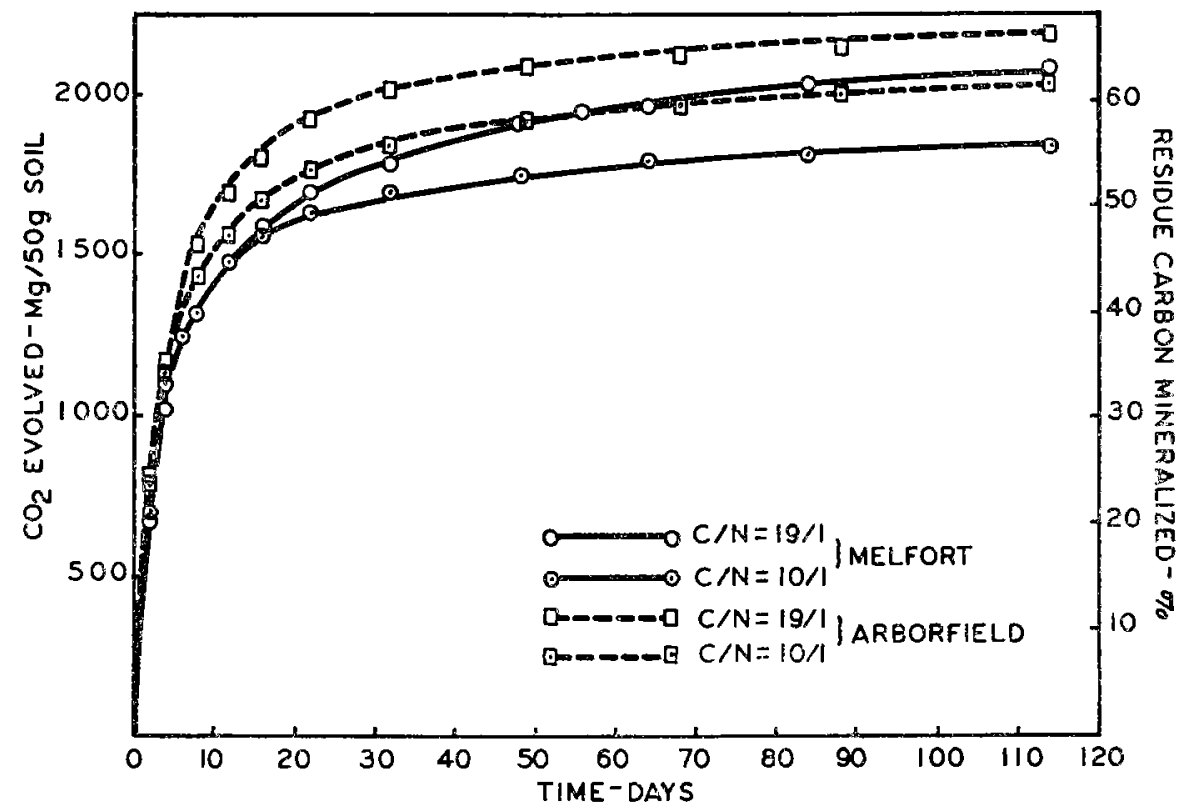

FIGURE 5. Effect of nitiogen on cumulative $\mathrm{CO}_{2}$ evolution from soils incubated with 40 tons of alfalfa per acre.

\section{Decomposition of Sphagnum Peat, Cellulose and Glucose}

Sphagnum peat incorporated into the soil was decomposed at an extremely slow rate (Figure 6). With an application equivalent to 40 tons per acre, only 3 per cent and 4 per cent was decomposed during 5 months in the Arborfield and Melfort soils, respectively. Nitrogen additions to reduce the natural $\mathrm{C} / \mathrm{N}$ ratio of the peat from $60 / 1$ down to $10 / 1$ lowered this rate further. The peat had a $\mathrm{pH}$ of 3.5 , and reduced the $\mathrm{pH}$ of both soils by approximately 0.7 units. The addition of ammonium nitrate further increased the acidity so that the Melfort soil dropped from an original $\mathrm{pH}$ value of 6.4 down to 4.8 . The increased acidity did not, however, inhibit

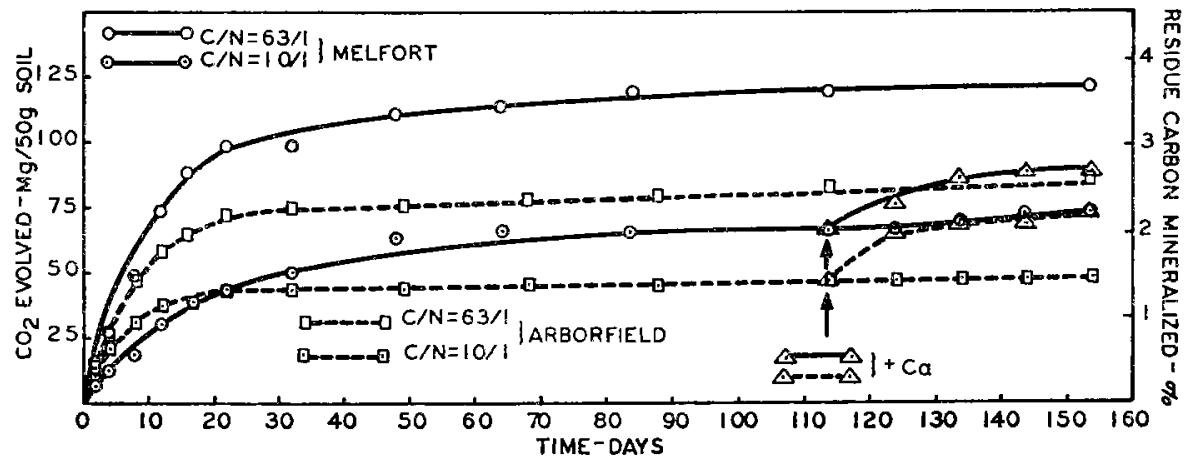

Figure 6. Effect of nitrogen and calcium on cumulative $\mathrm{CO}_{2}$ evolution from soils incubated with 40 tons of sphagnum peat per acre. 


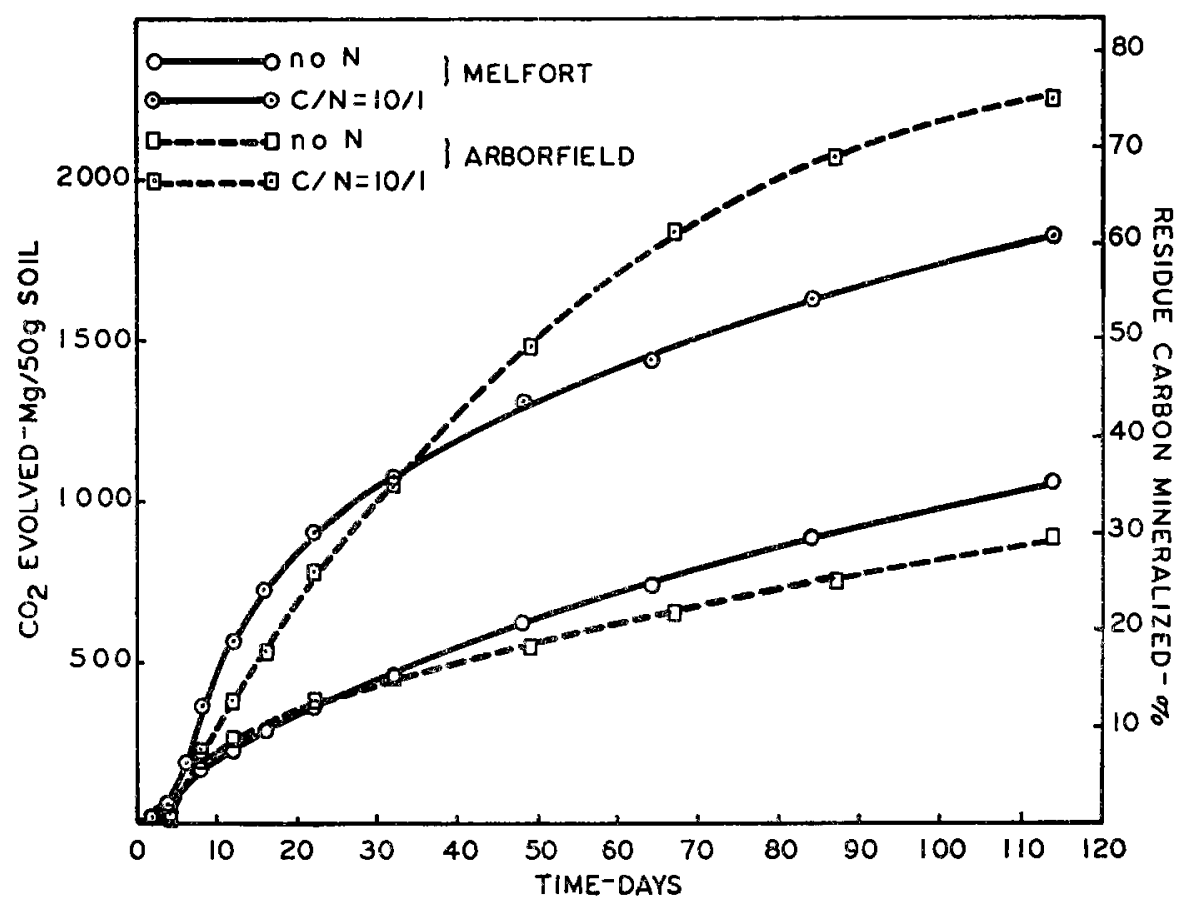

Frgure 7. Effect of nitrogen on cumulative $\mathrm{CO}_{2}$ evolution from soils incubated with 40 tons of cellulose per acre.

mineralization of the residue for neutralization of both soils with calcium hydroxide resulted in a slight flush of activity which tended to level off after 14 days (Figure 6).

The depression of evolution of $\mathrm{CO}_{2}$ by the addition of nitrogen to alfalfa, wheat straw, and peat residues in the soil indicated that the addition of nitrogen should lead to the formation of increased amounts of soil humus. Since this observation is somewhat contentious, the effect of nitrogen on the decomposition of cellulose and glucose was also investigated. Cellulose adjusted to a carbon to nitrogen ratio of $10 / 1$ and, incorporated in both soils, had an initial decomposition rate almost double that of the soil-cellulose mixture without added nitrogen (Figure 7). The reversal in decay rates due to nitrogen, which was observed for aimost all other residue treatments, did not however occur during 114 days of incubation.

The addition of nitrogen with glucose, which is also a nitrogen-free compound, resulted in decomposition trends opposite to those observed with cellulose and in agreement with those for straw and alfalfa (Figures 2, 3, $4,5)$. The added nitrogen only caused a significant increase in the rate of $\mathrm{CO}_{2}$ evolution during the first few days of incubation. Thus, when nitrogen was supplied to the Melfort soil with glucose, approximately 60 per cent of the glucose carbon was oxidized within the first 4 days of incubation. Nevertheless, the nitrogen-treated samples had a lower net evolution of $\mathrm{CO}_{2}$ 


\begin{tabular}{|c|c|c|c|c|c|c|c|}
\hline \multirow{5}{*}{ 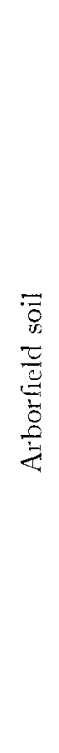 } & 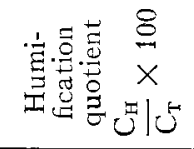 & $\stackrel{1}{8}$ & 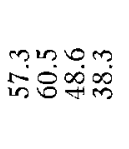 & 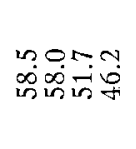 & $\begin{array}{l}0 \infty \\
\dot{f}+\dot{+}\end{array}$ & 11 & $\begin{array}{l}3 \% \\
\text { सैं }\end{array}$ \\
\hline & 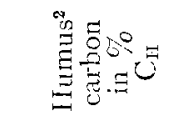 & $\stackrel{\vec{S}}{-}$ & 88. & 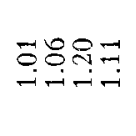 & 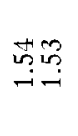 & 11 & $\stackrel{2}{3}$ \\
\hline & 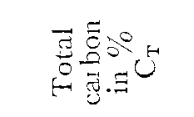 & 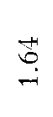 & 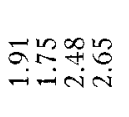 & 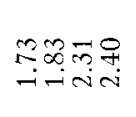 & 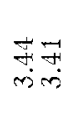 & 11 & $\overline{5} \overline{-i}$ \\
\hline & 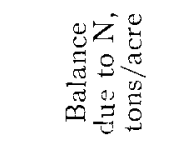 & & 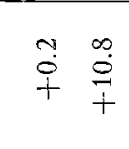 & $\begin{array}{ll}\ddot{0} & 0 \\
+ & +\end{array}$ & $\stackrel{n}{0}$ & $\begin{array}{c}0 \\
\infty \\
1\end{array}$ & $\begin{array}{l}\infty \\
\dot{1} \\
+\end{array}$ \\
\hline & 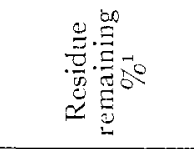 & & œ 궁ㅇํ & $\ddot{2} \ddot{n}+\infty$ & $\hat{a} \alpha$ & 유 & $\stackrel{2}{2}=$ \\
\hline \multirow{5}{*}{ 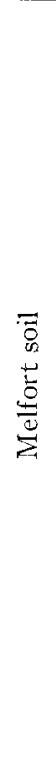 } & 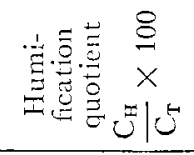 & 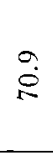 & 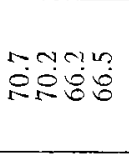 & 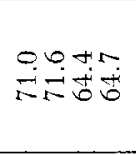 & ì & 11 & $\begin{array}{l}\infty \text { y } \\
810\end{array}$ \\
\hline & 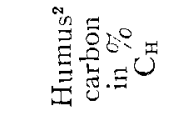 & $\vec{m}$ & 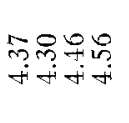 & 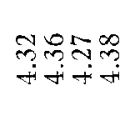 & 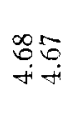 & 11 & $\begin{array}{l}\partial \tilde{y} \\
\dot{m}+\end{array}$ \\
\hline & 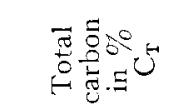 & $\stackrel{\infty}{0}$ & $\begin{array}{l}\infty= \pm 0 \\
-1000 \\
6060\end{array}$ & 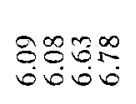 & 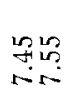 & $1:$ & $\begin{array}{l}\text { s. } \\
\text { in }\end{array}$ \\
\hline & 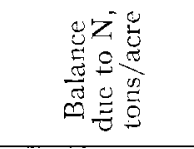 & & \begin{tabular}{ll}
\multirow{2}{*}{} & $\stackrel{2}{\leftarrow}$ \\
+ & +
\end{tabular} & $0 \stackrel{\infty}{i}$ & $\stackrel{0}{\dot{+}}$ & $\frac{0}{1}$ & $\begin{array}{l}0 \\
i \dot{0} \\
+\end{array}$ \\
\hline & 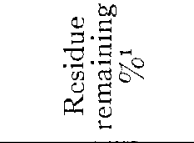 & & 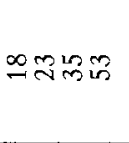 & 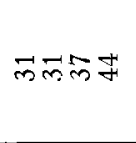 & $\stackrel{2}{\circ}$ & పేరి & $p=$ \\
\hline & zo. & & $\begin{array}{l}-15= \\
8080\end{array}$ & 흥ㅎㅇㅇㅡ & 항음 & 르을 & 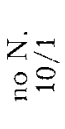 \\
\hline & 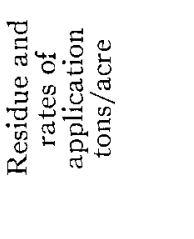 & 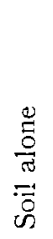 & 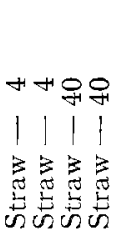 & 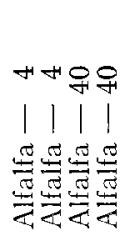 & 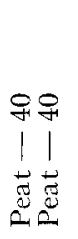 & 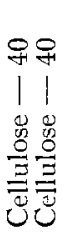 & 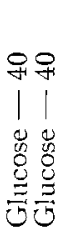 \\
\hline
\end{tabular}


for, in the nitrogen-treated samples, the rates of mineralization decreased to a markedly low level after the initial flush of activity during the first few days. The Melfort soil plus glucose, without supplemental nitrogen, demonstrated a net loss of organic carbon, whereas the addition of nitrogen decreased the $\mathrm{CO}_{2}$ evolution 15 per cent (equivalent to 4.4 tons of glucose per acre).

An organic matter fractionation of the various incubated soils was carried out on samples after 100 days of incubation. According to the principle of Springer's sulphacetolysis separation $(13,15)$, non-humified and partially humified materials are separated and thus go into solution. The humus fractions, which are not as reactive, are not dissolved. The humification quotient $\frac{\text { non-extractable carbon }\left(\mathrm{C}_{\mathrm{H}}\right)}{\text { total organic carbon }\left(\mathrm{C}_{\mathrm{T}}\right)} \times 100$ is a relative measure of the stable soil humus. The results in Table 3 indicate that the humification quotients of the Arborfield soil samples for both the untreated and treated soils were lower than those obtained for the corresponding treatments in the Melfort soil. This is in agreement with the generally accepted view that the Black soils (Melfort) contain a higher ratio of more stable humus compounds than do the Grey (Arborfield) soils.

Residue application, especially at the higher rates of application, resulted in a marked lowering of the humification quotient. This was especially true for the peat treatments which were resistant to microbial attack to the extent that 97 per cent of residue remained after 154 days' incubation. The peat residue was, however, removed by the sulphacetolysis treatment and, although resistant to microbial attack, could thus not be considered to be humified.

Nitrogen additions to the glucose- and straw-treated samples resulted in the retention of an extensive amount of residue. The humification quotient of the Arborfield soil dropped as a result of the increased residue. In the Melfort soil, however, although as much as 7 tons of residue were retained due to the added nitrogen, the humification quotient was identical to the non-nitrogen-treated sample.

\section{Structural Development of Two Soils under the Influence of Various Residue Applications and Carbon to Nitrogen Ratios}

Treatments as used for the 5 -month $\mathrm{CO}_{2}$ evolution test were duplicated for both soils in a parallel set-up in order to permit some chemical and physical analyses, without disturbing the samples on which the $\mathrm{CO}_{2}$ measurements were being made. These latter soils were incubated in Neubauer dishes, and the moisture content was kept at 70 per cent of the field capacity. Mechanical stirring was carried out once a month.

The soils developed characteristic structures during the 5-month period, indicating a distinct relationship with the applied treatments. This was particularly apparent for the Arborfield soil, which is characterized by weakly developed structure and tends to puddle when water is applied. Figure 8 shows the structural development of Arborfield soils incubated with glucose, straw and cellulose residues, with additional nitrogen in some cases. 
The higher treatments were fully effective in diminishing the surface sealing, and in producing aggregates which withstood the dispersing action of applied water.

The type of residue influenced structural development to different degrees. Alfalfa produced a more friable structure than straw. Peat created a spongy structure in both soils (not shown), but no crumb formation was observed and surface sealing was aggravated. Glucose tended to cause the formation of hard non-friable aggregates, particularly in the Arborfield soil.

The addition of nitrogen had a favorable influence on structural development of most of the residue-soil mixtures. Although surface sealing appeared to be aggravated, the nitrogen treatment produced a finer aggregation and a greater friability in the straw, cellulose and glucose treatments. The alfalfa and peat treatments were not affected by nitrogen additions.

\section{DISCUSSION AND SUMMARY}

Results from this study indicate that added nitrogen affected residue decomposition and organic matter accumulation in two distinct ways. Nitrogen accelerated the initial decay rate of incorporated residues. This trend was, however, later reversed so that larger amounts of organic carbon were maintained when supplemental nitrogen was applied. This was true for all residues, except cellulose, which showed a consistently higher rate of decomposition when nitrogen was added. This suggests that a substantial nitrogen deficiency occurred only in the cellulose-treated samples. In all other treatments, after the initial flush of activity due to the added nitrogen, the second effect of nitrogen predominated, namely the formation of humified organic matter. Andrews (1) observed a similar phenomenon. He obtained high positive correlation coefficients between the nitrogen content of rye straw and the rates of $\mathrm{CO}_{2}$ evolution during the first month of incubation. Thereafter, the correlation coefficient became negative and was as high as -0.853 at the end of the fourth month of incubation. The total carbon loss was, nevertheless, higher in the high nitrogen samples. It must be considered, however, that, in the experiment conducted by Andrews, only about one-half of the incorporated residue had been decomposed at the end of the experiment. The total effect of nitrogen on residue decomposition can thus only be measured by carefully controlled experiments extending over a long incubation period.

The decomposition of glucose was most advanced at all times during the decomposition period. Differences in total glucose decomposed due to nitrogen were quite apparent for the Melfort soil, but were just beginning to be discernible in the Arborfield soil. For the Melfort soil, a net gain equivalent to 4.4 tons of organic matter per acre was derived from the glucose residue with supplemental nitrogen. This compared very favorably with a net loss of 1.2 tons in the non-nitrogen-treated sample.

The humus fractionation tests disclosed the interesting fact that the sulphacetolysis extraction technique does differentiate between residue carbon and the more polymerized humus fraction. In the Melfort soil the 

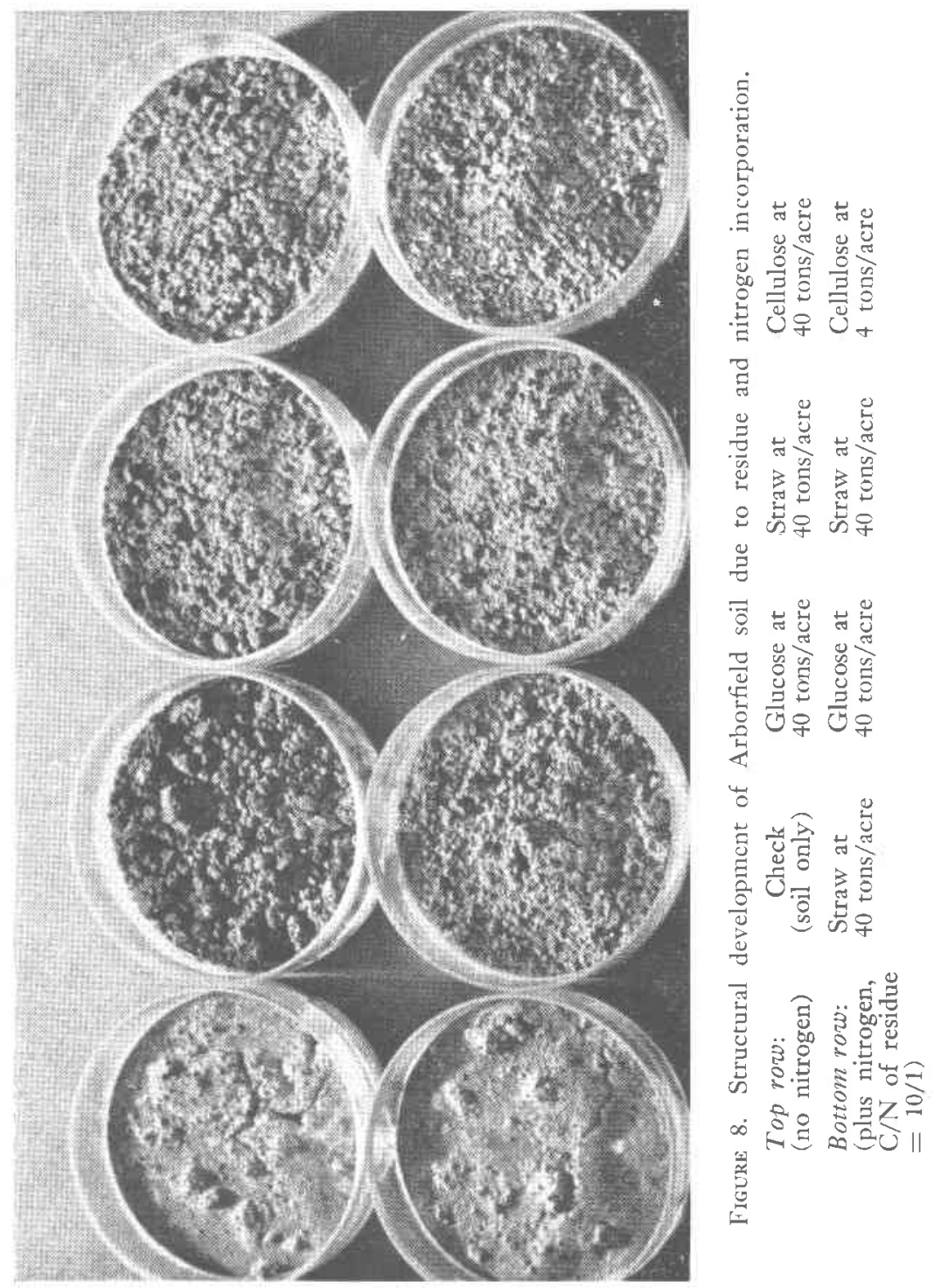


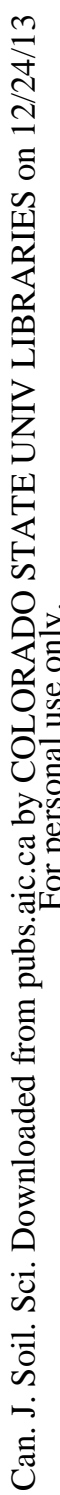


addition of nitrogen, although resulting in a substantial saving of organic carbon, did not result in a lowering of the humification quotient. This was not apparent in the Arborfield soil, perhaps due to the less advanced degree of decomposition of the incorporated residues.

The initially available nitrogen content of the soil, the mineral composition of the residues, and their major organic constituents, such as carbohydrates, proteins, lignins, fats and waxes will all affect the decomposition characteristics. Thus, the extremely low rates of mineralization of sphagnum peat residues, whether incubated with or without nitrogen, were due to the composition of the residue rather than to soil type or amendment.

The two soils utilized in this study differed markedly in physical and chemical characteristics. No fundamental differences were observed in the general character of the decomposition curves. The respiration of both soils was approximately equivalent in magnitude. However, it is noteworthy that there was a very significant difference in the structural changes between the two soils.

Although added nitrogen initially stimulated decomposition, there was no evidence (except for pure cellulose) that a lack of nitrogen inhibited the breakdown of the added residues. Under field conditions in Western Canada, mineralization of soil organic matter, especially in a summerfallow rotation, probably supplies adequate nutrients for residue decomposition and for growth of the following crop. The advantages to be gained by adding nitrogen to lower the losses of carbon from the added residues would not justify the expense, unless the crops respond to the added nutrients.

\section{REFERENCES}

1. Andrews, W. B. 1935. The effect of nitrogen content of rye on its rate of decomposition. Soil Sci. 40:219-221.

2. Jenny, H. 1930. Study on the influence of climate upon the nitrogen and organic matter content of the soil. Mo. Agr. Expt. Sta. Research Bull. 152.

3. Lee, Ching-Kwei, and R. H. Bray. 1949. Organic matter and nitrogen contents of soils as influenced by management. Soil Sci. 68:203-212.

4. Merkle, F. G. 1918. The decomposition of organic matter in soils. J. Amer. Soc. Agron. 10:281-302.

5. Mitchell, J., H. C. Moss, and J. S. Clayton. Soil Survey Report 12, 1944; and 13, 1950. Univ. of Saskatchewan, Saskatoon.

6. Newton, J. D. 1956. Microbial and nutritional effects of "trash cover" in Western Canada's Grey Wooded, Black Earth and Brown Prairie soils. Trans. Intern. Congr. Soil Sci. 6th Congr. III:213-223.

7. Peevy, W. J., and A. G. Norman. 1948. Influence of composition of plant materials on properties of the decomposed residues. Soil Sci. 65:209-226.

8. Pinck, L. A., F. E. Allison, and M. S. Sherman. 1950. Maintenance of soil organic matter. II. Losses of carbon and nitrogen from young and mature plant materials during decomposition in soil. Soil Sci. 69:391-401.

9. Reissig, H. 1956. Characterisierung der Humuscomponente von Schwarzerden verschiedener Herkunft. Z. Pflanzenernähr., Dung., Bodenkunde 74:112-127.

10. Salter, F. J. 1931. The carbon-nitrogen ratio in relation to the accumulation of organic matter in soils. Soil Sci. 31:413-430.

11. Siegel, O. 1940. Mehriährige Beobachtungen über den Abbau und die Humifizierung Organischer Stoffe im Boden. Bodenkunde, und Pflanzenernähr. 21/22:455-473.

12. Sievers, F. J., and H. F. Holtz. 1928. The significance of nitrogen in soil organic matter relationships. Proc. 1st Intern. Congr. Soil Sci. Comm. IV, pp. 423-436. 
13. Springer, U., and A. Lehner. 1952. Stoffabbau und Humusaufbau bei der aeroben und anaeroben Zersetzung Landwirtschaftlich und Forstwirtschaftlich wichtiger Organischer Stoffe. Z. Pflanzenernähr., Dung., Bodenkunde 58:193-231.

14. Truog, E., and A. H. Meyer. 1929. Improvements in the Denigès colorimetric method for phosphorus and arsenic. Ind. Eng. Chem. Anal. Ed. 1:136

15. Thun, R., R. Herrmann, und E. Knickmann. 1955. Methodenbuch. Band 1. Die Untersuchung von Boden. 3. Aufl. Neumann Verlag, Radebeul und Berlin.

16. Turk, L. M., and C. E. Millar. 1936. The effect of different plant materials, lime and fertilizers on the accumulation of soil organic matter. J. Amer. Soc. Agron. 28:210-324.

17. Waksman, S. A., and F. G. Tenny, 1927. The composition of natural organic materials and their decomposition in the soil. II. Influence of age of plant upon the rapidity and nature of its decomposition in rye plants. Soil Sci. 24: $317-333$ 